\title{
T1 Relaxation Times in the Rotating Frame for Assessing a Liver Injury-and-Recovery Animal Model
}

\section{Genwen Hu}

Shenzhen People's Hospital

\section{Xianyue Quan}

Zhujiang Hospital

\section{Liangping Luo}

Jinan University First Affiliated Hospital

Jianmin Xu

Shenzhen People's Hospital

\section{Yingjie Mei}

Philips Healthcare

\section{Yufa Li}

Guangdong General Hospital

\section{Zhong Yang}

Shenzhen People's Hospital

Jinsen Zou (D 334742523@qq.com )

Shenzhen People's Hospital https://orcid.org/0000-0002-0676-6096

Yanhui Chen

Shenzhen People's Hospital

\section{Research article}

Keywords: T1rho, Liver fibrosis. CCl4, Collagen

Posted Date: May 10th, 2021

DOI: https://doi.org/10.21203/rs.3.rs-496404/v1

License: (a) (1) This work is licensed under a Creative Commons Attribution 4.0 International License. Read Full License 


\section{Abstract}

Background: To explore the relationship between the T1 relaxation times in the rotating frame (T1rho) and pathophysiology in a liver injury-and-recovery animal model.

Methods: Male Sprague-Dawley rats $(n=80)$ were randomly assigned to two groups: group A involved carbon tetrachloride (CCl4) injury and withdrawal, and group $B$ involved bile duct ligation (BDL) and recanalization. Time-points $(n=8)$ for 3.0T MRI and histological examination were: Group A on day 0,15 , and 40 after the first injection, and day 10, and 25 after injection withdrawal; Group B on day 0,6 , and 10 after obstruction, and day 6 , and 13 after recanalization. calculated to assess the correlation between the T1rho and the histopathological parameters.

Results: Collagen content, steatosis, ballooning, and inflammation increased in both groups with injury time and decreased with recovery time (withdrawal and recanalization). The T1rho values displayed the same trend. Significant correlation between the T1rho values and collagen was found in the both group $A$ and group $B(r=0.547, r=0.575, p<0.001)$. Moreover, both group $A$ and group $B$ was correlated with steatosis $(r=0.598, r=0.594, p<0.001)$, ballooning $(r=0.616, r=0.642, p<0.001)$, and inflammation $(r=0.636, r$ $=0.641, \mathrm{p}<0.001)$.

Conclusion: Overall, the T1rho value appears to reflect the process of injury-and-recovery of the liver. Nevertheless, the T1rho value does not exhibit a simple one-to-one correlation with a single factor, such as collagen.

\section{Background}

The $\mathrm{T} 1$ relaxation time in the rotating frame ( $\mathrm{T} 1 \mathrm{rho}$ or $\mathrm{T} 1 \rho)$ value represents the relaxation time constant of biological tissue in the presence of radiofrequency (RF) pulses (spin lock RF pulses). The B1 amplitude of the spin-lock RF pulses is much weaker than the main magnetic field strength $\mathrm{B} 0$, which makes the T1rho relaxation time sensitive to low-frequency motion processes in biological tissues [1].

Previous studies have shown that T1rho can detect early pathological changes in the liver and is highly related to the degree of fibrosis at both 1.5 and 3.0T MRI field strengths [2-4]. This suggests that T1 rho can be used for the early detection and grading of liver fibrosis. Previous studies have focused on the different stages of liver fibrosis, however, the classification thereof was mainly based on the distribution and quantity of collagen within the liver. It has also been recently reported that elevated T1 rho values are significantly correlated with Child-Pugh stages, which depend on the amount of collagen in the liver [3]. Nevertheless, Takayama et al [5] reported conflicting results in that the liver T1rho value was not significantly correlated with the stage of liver fibrosis.

The relationship between T1rho values and histopathology, as well as the fundamental mechanism leading to the elevated T1rho values in liver fibrosis and cirrhosis remain unclear. Most previous studies only constructed an injury animal model, but did not include the corresponding repair model. Therefore, we designed an injury-and-repair animal model induced by carbon tetrachloride (CCl4) and bile duct ligation (BDL), respectively, to study the alterations of T1rho values and to explore the possible relationship between the T1rho value and the histopathology of the tissue of interest.

\section{Materials And Methods}

\section{Animal model:}

Male Sprague-Dawley rats ( $n=80$, weight: $200 \pm 20 \mathrm{~g}$ ) were provided by the Experimental Animal Center of our University, Guangdong, China (Animal permit number: SCXK2014-0035). Rats were housed at $18-20^{\circ} \mathrm{C}, 60-70 \%$ humidity, and on a 12 hour light/dark cycle. During the experimental period, animals were fed with distilled water and standard rat feed. All experimental procedures were approved by the Institutional Animal Ethics Committee and were performed according to the Laboratory Animal Care and Usage Manual.

\section{Experimental groups:}

At the beginning of the study, all rats were randomly assigned to two experimental groups. Group A animals underwent a carbon tetrachloride ( $\mathrm{CCl} 4)$ injury and subsequent withdrawal for recovery according to a previous protocol [6]. In short, rats were injected 
with $50 \% \mathrm{CCl} 4$ (CCl4:olive oil in a 1:1 ratio) $(0.3 \mathrm{ml} / 100 \mathrm{~g}$ bodyweight) subcutaneously twice per week until day 40 .

Group B animals underwent bile duct ligation (BDL) and recanalization. Rats were initially anesthetized with $3 \%$ pentobarbital (0.2 $\mathrm{ml} / 100 \mathrm{~g}$ bodyweight) by intraperitoneal injection [7]. Then, after an abdominal incision, the common bile duct was exposed aseptically, separated, and ligated near the liver below the bifurcation. The bile duct was then recanalized on day 10 .

The time points for MRI scanning and histological examination for both study groups $(n=8)$ are shown in Figure 1 . The MRI time points were decided based on our previous studies [7].

\section{Magnetic resonance imaging:}

MRIs were acquired with an INGENIA 3.0T scanner (Philips Healthcare, Best, Netherlands) with a 4-channel animal coil (ShuZhou ZONGZHI Medical Technologies Co.). Rats were sedated using $3 \%$ sodium pentobarbital ( $0.2 \mathrm{ml} / 100 \mathrm{~g}$ bodyweight $)$ via intraperitoneal injection and placed in the prone position. The standard sequences used for scanning include the following: (A) axial and coronal T2-weighted fast field echo (2D-FFE), repetition time/echo time (TR/TE): 203/9.2 ms, field of view (FOV): $60 \times 60 \mathrm{~mm}$, slice thickness: 3 mm, matrix: 100×100; (B) axial T1 weighted turbo spin-echo (TSE), TR/TE: 400/10ms, FOV: 60×60 mm; matrix: 120×93; slice thickness: $3 \mathrm{~mm}$.

The T1rho was determined using an adiabatic RF pulse with the following parameters: TR/TE: 4.9/2.4 ms; FOV: $60 \times 60 \mathrm{~mm}$; flip angle: 40; Matrix: 100×100; slice thickness: $3 \mathrm{~mm}$; number of slices: 5; spin lock frequency: $500 \mathrm{~Hz}$; rotation lock times: 0, 27, and 54 milliseconds.

MRI data analysis:

The T1rho images were fitted to an exponentially decaying T1rho function on a pixel-by-pixel basis to generate a T1rho relaxation map with the IDL software (Research Systems, Inc., USA). T1 rho values were computed using a mono-exponential decay model, as seen in Eq. 1, where $M_{T S L}$ is the magnetization and TSL is the time of the spin-lock pulse.

$$
M_{T S L}=M_{0} * e^{\frac{-T S L}{T 1 r h o}} \quad \text { Eq. } 1
$$

The data was analyzed using the Image J software ( $\mathrm{NIH}$, Bethesda, MD, USA). Five regions of interest (ROIs) of approximately 3-4 $\mathrm{mm} 2$ were drawn manually to avoid the inclusion of the liver margin, vessels, and bile ducts. The mean values obtained for the five ROIs were considered as the T1 rho values

\section{Blood serum parameters of liver function}

After centrifugation for $10 \mathrm{~min}$ at $4^{\circ} \mathrm{C}(300 \times \mathrm{g}$; Centrifuge 5804R), the activity of alanine transaminase (ALT), aspartate aminotransferase (AST) and total bilirubin (TBIL) in the serum was determined using an automatic biochemical blood analyzer (cat. no. 7600-210; Hitachi High-Technologies Corporation).

\section{Histopathological examination:}

After the MRI scan, the rats were sacrificed via excessive anesthesia. The liver tissue was removed, fixed with a formaldehyde solution and embedded in paraffin. The tissue was then cut into $5-\mu \mathrm{m}$ sections and stained with hematoxylin and eosin (HE) and picrosirius red. Here, picrosirius staining reflects collagen content and indicates progressive changes in fibrosis after the reversal of bile duct obstruction. Two independent pathologists blinded to the MRI results evaluated the samples using a dedicated microscope (Leica DM2000).

The collagen content of the liver was measured using a semi-quantitative analysis with picrosirius staining. Briefly, ten parenchymal images of the liver (magnification of 200x) were randomly selected and the percentage of positively stained areas relative to the entire area was calculated using the Image-Pro Plus v6.0 image analysis software (Media Cybernetics, Rockville, MD) [8, 9].

Inflammation, ballooning, and steatosis in the liver were evaluated according to the nonalcoholic steatohepatitis (NASH) standards [10]. Lobular inflammation was graded on a 0-3 scale: 0: no lesions; 1: <2 lesions; 2: 2-4 lesions; 3: >4 lesions. Portal inflammation was graded on a 0-1 scale: 0: none to minimal; 1: greater than minimal. Ballooning was graded on a 0-2 scale: 0: none; 1: few balloon 
cells; 2: many cells/prominent ballooning. The assessment of steatosis was based on the proportion of the steatosis area within the visual field [11].

\section{Statistical Analysis:}

The statistical package for social sciences software version 20.0 (SPSS, Chicago, IL) was used for all statistical analysis. A p-value $<0.05$ was considered statistically significant. The data are expressed as mean \pm standard deviation. Normality was assessed using a Kolmogorov-Smirnov test. A one-way analyses of variance for multiple groups with least significant difference post hoc tests was performed on the outcome parameters. Pearson's rank correlation coefficients, ( $r$ values) were calculated to assess the correlation between the T1rho and the pathophysiological parameters.

\section{Results}

\section{Histopathological examinations:}

Group A: carbon tetrachloride (CCl4) injury and withdrawal:

The results showed that rats developed liver fibrosis after the prolonged injection of CCl4. On the 15th day after injection, HE-stained sections showed the liver lobular structure with a large aPagmount of steatosis. On the 40th day, the liver injury was most severe with a collagen content of $21.88 \% \pm 5.79$, inflammation score of $1.63 \pm 0.52$, ballooning score of $1.50 \pm 0.53$, and steatosis score of 26.88 \pm 8.84. Meanwhile, on the 25th day of CCl4 withdrawal, the collagen content receded to $10.88 \% \pm 3.60$, the inflammation score to 0.63 \pm 0.51 , the ballooning score to $0.25 \pm 0.46$, and the steatosis score to $1.50 \pm 2.14$, indicating a near total recovery from injury (Figure 2 , Table 1).

Group B: bile duct ligation (BDL) and recanalization:

On the $6^{\text {th }}$ day after BDL, the bile ducts were dilated and a small amount of collagen appeared around the tubules. On the $10^{\text {th }}$ day after BDL, injury to the liver was most severe with a collagen content of $10.63 \% \pm 3.20$, an inflammation score of $1.88 \pm 0.35$, a ballooning score of $0.50 \pm 0.53$, and a steatosis score $6.63 \pm 1.85$. As time progressed, on the 13 th day of BDL reopening, the collagen content reduced to $4.13 \% \pm 1.81$, the inflammation score to $0.50 \pm 0.53$, the ballooning score to $0.13 \pm 0.35$, and the steatosis score to $4.50 \pm 2.45$ (Figure 3, Table 2).

\section{MRI parameters:}

In in both groups, the T1rho value increased after injury and decreased after injury reversal (withdrawal and recanalization). However, the T1rho value did not return to the baseline level after injury reversal in either groups (Table1-2, Figure 3-4).

\section{Correlation of the T1rho value with histopathological examinations and blood serum parameters of liver function}

A Pearson's rank correlation test showed that the T1rho values and collagen content was significantly correlated in group A ( $r=0.575$, $p<0.001)$ and group B $(r=0.547, p<0.001)$. Moreover, the T1rho values in both group A and B was significantly correlated with steatosis $(r=0.598, p<0.001 ; r=0.594, p<0.001)$, ballooning $(r=0.616, p<0.001 ; r=0.642, p<0.001)$, and inflammation $(r=0.636$, $p<0.001 ; r=0.641, p<0.001)$. The T1rho value in group A and B was significantly correlated with TBIL $(r=0.503, p<0.001 ; r=0.569$, $p<0.001)$, ALT $(r=0.595, p<0.001 ; r=0.408, p<0.001)$, and AST $(r=0.581, p<0.001 ; r=0.517, p<0.001)$.

\section{Discussion}

Liver fibrosis is the common tissue repair response to chronic damage caused by various factors, such as excessive deposition of extracellular matrix components that include collagen and proteoglycans. An increase in the liver T1rho value may be due to the accumulation of collagen and mutative chemical exchange. Collagen is often causes macromolecules to undergo a static process and to move slowly [12]. The T1rho value is sensitive to both low-frequency motion and static processes, and has been implicated in the investigation of macromolecular composition and proton exchange within tissues [13]. The spin locking sequence using stretchtype adiabatic pulses provides homogeneous liver T1rho maps with reduced artifacts and is necessary for a robust evaluation of liver function using the T1rho metric $[14,15]$. 
Previous studies have shown that an elevated T1rho value is positively correlated with the severity of liver fibrosis $[2,3,16]$. Similarly, it has been observed that an elevated T1rho value is correlated with the amount of collagen deposition in biliary duct ligation-induced liver fibrosis [2]. Akella et al. also found that proteoglycan levels are correlated with T1rho values in articular cartilage [17]. Based on this evidence, it seems that the increase in T1rho values is closely related to the presence of collagen and proteoglycans.

CCL4-induced liver fibrosis in rats is a frequently used animal model for liver fibrosis. In this model, after the injection of CCL4, liver cells gradually become damaged and the severity of liver fibrosis increases. Nevertheless, we found that after ceasing the CCL4 injection, the infiltration of inflammatory cells in rat liver tissue decreases, as does fibrous collagen, which is consistent with previous studies $[18,19]$. According to a recent study [19], inflammatory activity has a greater impact on liver T1 rho values than fibrosis. However, this work did not study the detailed pathological aspects thereof. In this study, in the liver injury animal model, the T1rho values were more correlated with inflammation, ballooning and steatosis than with collagen. This indicates that the T1rho value does not correspond to collagen in one-to-one fashion for every scenario.

As previously described, we found that liver fibrosis is associated with a number of complicated pathological processes with the exception of collagen. Hence, liver pathologies contributing to the T1 rho contrast require more careful evaluation. A similar viewpoint was also noted by Wang et at.[20] and further supported by Xie et al. in the sense that the T1rho value is not affected by a fatty liver [16]. However, our results show that liver steatosis is related to the T1rho value during liver injury-and-repair. We also found that the T1 rho value is related to inflammation and ballooning, and reflects the complex pathologies during injury-and-recovery. Previous studies investigating liver fibrosis have mainly focused on distinguishing the stage of fibrosis, which reflects the amount and distribution of collagen in the liver. Nevertheless, few works have examined the related comprehensive factors such as steatosis, ballooning and inflammation, which may also influence the T1rho value.

Some researchers have speculated that one of the reasons behind the inter-subject variability in the T1rho values may be related to the iron content in the liver and other sources [21,22]. This variability poses difficulties in accurately determining the causal role of

T1rho values and is a topic for further study. Additionally, Takayama et al. reported that the liver T1rho value was positively correlated with the serum inflammatory markers that include serum total bilirubin, direct bilirubin, and indocyanine green (ICG-R15) and negatively correlated with serum albumin and $\mathrm{y}$-glutamyl transpeptidase levels [5]. Our results indicate that the T1rho value is correlated with TBIL, ALT, and AST. The TBIL of the CCL4 and the BDL group was significantly different, however, the T1 rho value was not. Consequently, the mechanism of the variation in T1rho values in liver injury and recovery is still not clear and will require careful investigation in the future.

This study has several limitations that should be noted. First, we performed a semi-quantitative histopathological examination in the current work. Here, collagen content was determined by the photometric analysis of histological samples, which can be prone to sampling error compared to biochemical assays. Second, this study still failed to reveal the mechanism of the variation in T1rho values in liver injury and recovery. Future research should therefore focus on the correlation between T1rho values and steatosis, hepatocyte ballooning and inflammation.

\section{Conclusion}

The T1rho value exhibits a complex correlation with collagen content, however, reflects the comparatively complex pathological process that is comprised of inflammation, ballooning and steatosis that occur throughout liver injury and repair. Overall, the T1rho value appears to reflect the process of injury-and-recovery of the liver. However, the T1 rho value does not exhibit a simple one-to-one correlation with any single factor, such as collagen or total bilirubin (TBIL). Overall, this work suggests that T1rho imaging can be extended to the monitoring of treatment effectiveness.

\section{List Of Abbreviations}

T1 relaxation time in the rotating frame (T1 rho)

Carbon tetrachloride $(\mathrm{CCl} 4)$

Bile duct ligation (BDL)

Alanine transaminase (ALT)

Page 5/11 
Total bilirubin (TBIL)

\section{Declarations}

\section{Ethics approval and consent to participate}

The experimental procedures were approved by the Institutional Animal Ethics Committee and performed according to the Laboratory Animal Care and Usage Manual.

\section{Consent for publication}

Not applicable.

\section{Competing interests}

The authors declare that they have no competing interests.

\section{Availability of data and materials}

Not applicable.

\section{Funding}

This work was supported by grants from the Shenzhen Basic Research Plan Fund Project (No. JCYJ20180228164641207) and the Cultivating Fund Project of Shenzhen People's Hospital (No. SYKYPY201933). National Natural Science Foundation of China (No. $21317241,81971672)$. The funding bodies had no role in the design of the study, the collection, analysis, or interpretation of the data, or writing the manuscript.

\section{Authors' contributions}

Genwen Hu: Writing - original draft

Yanhui Chen: Software

Xianyue Quan: Project administration

Jianmin Xu: Methodology

Liangping Luo: Software

Yufa Li: Methodology

Yingjie Mei: Software

Zhong Yang: Writing review \& editing

Jinsen Zou: Writing review \& editing

HGW drafted the original manuscript. CYH participated in the data collection. LYF performed pathological examination. XJM, QXY and LLP participated in the design of the study and performed the statistical analysis. YZ and ZJS helped draft the manuscript. All authors read and approved the final manuscript.

\section{Acknowledgements}

Not applicable.

\section{References}


1. Zhao F, Yuan J, Deng M, Lu PX, Ahuja AT and Wang YX (2013) Further exploration of MRI techniques for liver T1rho quantification. Quant Imaging Med Surg 3:308-315. https://doi.org/10.3978/j.issn.2223-4292.2013.12.10

2. Wang YX, Yuan J, Chu ES, et al. (2011) T1rho MR imaging is sensitive to evaluate liver fibrosis: an experimental study in a rat biliary duct ligation model. Radiology 259:712-719. https://doi.org/10.1148/radiol.11101638

3. Allkemper T, Sagmeister F, Cicinnati V, et al. (2014) Evaluation of fibrotic liver disease with whole-liver T1 $\rho$ MR imaging: a feasibility study at 1.5 T. Radiology 271:408-415. https://doi.org/10.1148/radiol.13130342

4. Chen W, Chen X, Yang L, et al. (2018) Quantitative assessment of liver function with whole-liver T1rho mapping at 3.0T. Magn Reson Imaging 46:75-80. https://doi.org/10.1016/j.mri.2017.10.009

5. Takayama Y, Nishie A, Asayama Y, et al. (2015) T1 $\rho$ Relaxation of the liver: A potential biomarker of liver function. J Magn Reson Imaging 42:188-195. https://doi.org/10.1002/jmri.24739

6. Hu G, Chan Q, Quan X, et al. (2015) Intravoxel incoherent motion MRI evaluation for the staging of liver fibrosis in a rat model. J Magn Reson Imaging 42:331-339. https://doi.org/10.1002/jmri.24796

7. Hu G, Liang W, Wu M, et al. (2018) Staging of rat liver fibrosis using monoexponential, stretched exponential and diffusion kurtosis models with diffusion weighted imaging- magnetic resonance. Oncotarget 9:2357-2366. https://doi.org/10.18632/oncotarget.23413

8. Moriyama T, Kawada N, Ando A, et al. (1998) Up-regulation of HSP47 in the mouse kidneys with unilateral ureteral obstruction. Kidney Int 54:110-119. https://doi.org/10.1046/j.1523-1755.1998.00964.x

9. Sun L, Shen YL, Liu HJ, Hu YJ, Kang YL and Huang WY (2016) The expression of response gene to complement 32 on renal ischemia reperfusion injury in rat. Ren Fail 38:276-281. https://doi.org/10.3109/0886022x.2015.1120118

10. Kleiner DE, Brunt EM, Van Natta M, et al. (2005) Design and validation of a histological scoring system for nonalcoholic fatty liver disease. Hepatology 41:1313-1321. https://doi.org/10.1002/hep.20701

11. Hu G, Zhang X, Liang W, et al. (2016) Assessment of liver fibrosis in rats by MRI with apparent diffusion coefficient and T1 relaxation time in the rotating frame. J Magn Reson Imaging 43:1082-1089. https://doi.org/10.1002/jmri.25084

12. Petitclerc L, Gilbert G, Nguyen BN and Tang A (2017) Liver Fibrosis Quantification by Magnetic Resonance Imaging. Top Magn Reson Imaging 26:229-241. https://doi.org/10.1097/rmr.0000000000000149

13. Szyperski T, Luginbühl P, Otting G, Güntert P and Wüthrich K (1993) Protein dynamics studied by rotating frame $15 \mathrm{~N}$ spin relaxation times. J Biomol NMR 3:151-164. https://doi.org/10.1007/bf00178259

14. Okuaki T, Takayama Y, Nishie A, et al. (2017) T(1 $)$ mapping improvement using stretched-type adiabatic locking pulses for assessment of human liver function at 3T. Magn Reson Imaging 40:17-23. https://doi.org/10.1016/j.mri.2017.03.006

15. Yang Q, Yu T, Yun S, et al. (2016) Comparison of multislice breath-hold and 3D respiratory triggered T1 $\rho$ imaging of liver in healthy volunteers and liver cirrhosis patients in 3.0 T MRI. J Magn Reson Imaging 44:906-913. https://doi.org/10.1002/jmri.25253

16. Xie S, Li Q, Cheng Y, et al. (2017) Impact of Liver Fibrosis and Fatty Liver on T1rho Measurements: A Prospective Study. Korean J Radiol 18:898-905. https://doi.org/10.3348/kjr.2017.18.6.898

17. Akella SV, Regatte RR, Gougoutas AJ, et al. (2001) Proteoglycan-induced changes in T1rho-relaxation of articular cartilage at 4T. Magn Reson Med 46:419-423. https://doi.org/10.1002/mrm.1208

18. Li H, Li J, Huang C, Huang Y and Cheng J (2011) Correlative research between leptin and TGF- $\beta 1$ and the recovery on CCl4 induced hepatic fibrosis in rats. Chinese Pharmacological Bulletin 27:473-477. https://doi.org/

19. Xie S, Qi H, Li Q, et al. (2020) Liver injury monitoring, fibrosis staging and inflammation grading using T1rho magnetic resonance imaging: an experimental study in rats with carbon tetrachloride intoxication. BMC Gastroenterol 20:14. https://doi.org/10.1186/s12876-020-1161-3

20. Wáng YXJ, Chen W and Deng M (2017) How liver pathologies contribute to T1rho contrast require more careful studies. Quant Imaging Med Surg 7:608-613. https://doi.org/10.21037/qims.2017.10.02

21. Koon CM, Zhang X, Chen W, Chu ES, San Lau CB and Wáng YX (2016) Black blood T1rho MR imaging may diagnose early stage liver fibrosis: a proof-of-principle study with rat biliary duct ligation model. Quant Imaging Med Surg 6:353-363. https://doi.org/10.21037/qims.2016.08.11 
22. Weinfeld A, Lundin P and Lundvall O (1968) Significance for the diagnosis of iron overload of histochemical and chemical iron in the liver of control subjects. J Clin Pathol 21:35-40. https://doi.org/10.1136/jcp.21.1.35

\section{Tables}

Table 1. Summary of the liver parameters and serum biochemistry in group A: carbon tetrachloride (CCl4) injury and withdrawal.

\begin{tabular}{|c|c|c|c|c|c|c|c|c|c|c|}
\hline & $\begin{array}{l}\text { Time } \\
\text { (day) }\end{array}$ & $\begin{array}{l}n \\
(40)\end{array}$ & $\begin{array}{l}\text { T1rho } \\
\text { value } \\
\text { (ms) }\end{array}$ & $\begin{array}{l}\text { Collagen } \\
\text { content } \\
(\% \bigotimes\end{array}$ & $\begin{array}{l}\text { Inflammation } \\
\text { (Score) }\end{array}$ & $\begin{array}{l}\text { Ballooning } \\
\text { (Score) }\end{array}$ & $\begin{array}{l}\text { Steatosis } \\
(\% \rrbracket\end{array}$ & $\begin{array}{l}\text { TBIL } \\
(\mathrm{mg} / \mathrm{dl})\end{array}$ & $\begin{array}{l}\mathrm{ALT} \\
(\mathrm{u} / \mathrm{I})\end{array}$ & $\begin{array}{l}\text { AST } \\
(\mathrm{u} / \mathrm{I})\end{array}$ \\
\hline \multirow[t]{3}{*}{$\begin{array}{l}\text { CCL4 } \\
\text { injection }\end{array}$} & 0 & 8 & $\begin{array}{l}78.27 \\
\pm 6.46\end{array}$ & $\begin{array}{l}0.31 \pm \\
0.27\end{array}$ & $0.00 \pm 0.00$ & $\begin{array}{l}0.00 \pm \\
0.00\end{array}$ & $\begin{array}{l}0.00 \pm \\
0.00\end{array}$ & $\begin{array}{l}1.00 \pm \\
0.27\end{array}$ & $\begin{array}{l}24.79 \pm \\
12.08\end{array}$ & $\begin{array}{l}94.80 \pm \\
67.48\end{array}$ \\
\hline & 15 & 8 & $\begin{array}{l}92.85 \\
\pm 7.41\end{array}$ & $\begin{array}{l}9.38 \pm \\
3.66\end{array}$ & $1.13 \pm 0.35$ & $\begin{array}{l}0.50 \pm \\
0.53\end{array}$ & $\begin{array}{l}22.88 \pm \\
14.99\end{array}$ & $\begin{array}{l}3.39 \pm \\
1.17\end{array}$ & $\begin{array}{l}160.17 \\
\pm 41.70\end{array}$ & $\begin{array}{l}461.21 \pm \\
212.62\end{array}$ \\
\hline & 40 & 8 & $\begin{array}{l}96.14 \\
\pm 6.41\end{array}$ & $\begin{array}{l}21.88 \pm \\
5.79\end{array}$ & $1.63 \pm 0.52$ & $\begin{array}{l}1.50 \pm \\
0.53\end{array}$ & $\begin{array}{l}26.88 \pm \\
8.84\end{array}$ & $\begin{array}{l}5.38 \pm \\
1.16\end{array}$ & $\begin{array}{l}241.04 \pm \\
65.87\end{array}$ & $\begin{array}{l}805.49 \\
\pm 153.85\end{array}$ \\
\hline \multirow[t]{2}{*}{$\begin{array}{l}\text { Injection } \\
\text { discontinued }\end{array}$} & 10 & 8 & $\begin{array}{l}87.67 \\
\pm 9.17\end{array}$ & $\begin{array}{l}13.13 \pm \\
4.39\end{array}$ & $1.00 \pm 0.53$ & $\begin{array}{l}0.63 \pm \\
0.52\end{array}$ & $\begin{array}{l}8.50 \pm \\
5.66\end{array}$ & $\begin{array}{l}3.08 \pm \\
0.89\end{array}$ & $\begin{array}{l}77.25 \\
\pm 27.75\end{array}$ & $\begin{array}{l}222.63 \\
\pm 60.64\end{array}$ \\
\hline & 25 & 8 & $\begin{array}{l}81.58 \\
\pm 6.78\end{array}$ & $\begin{array}{l}10.88 \pm \\
3.60\end{array}$ & $0.63 \pm 0.51$ & $\begin{array}{l}0.25 \pm \\
0.46\end{array}$ & $\begin{array}{l}1.50 \pm \\
2.14\end{array}$ & $\begin{array}{l}2.42 \pm \\
1.08\end{array}$ & $\begin{array}{l}63.50 \pm \\
15.23\end{array}$ & $\begin{array}{l}191.75 \\
\pm 71.79\end{array}$ \\
\hline p & & & $<0.001$ & $<0.001$ & $<0.001$ & $<0.001$ & $<0.001$ & $<0.001$ & $<0.001$ & $<0.001$ \\
\hline
\end{tabular}

CCL4: Carbon tetrachloride. P: One-way analysis of variance (ANOVA) for multiple group comparisons of parameters.

Table 2. Summary of the liver parameters and serum biochemistry in group B: bile duct ligation (BDL) and recanalization.

\begin{tabular}{|c|c|c|c|c|c|c|c|c|c|c|}
\hline & $\begin{array}{l}\text { Time } \\
\text { (day) }\end{array}$ & $\begin{array}{l}n \\
(40)\end{array}$ & $\begin{array}{l}\text { T1rho } \\
\text { value } \\
\text { (ms) }\end{array}$ & $\begin{array}{l}\text { Collagen } \\
\text { content } \\
(\% \otimes\end{array}$ & $\begin{array}{l}\text { Inflammation } \\
\text { (Score) }\end{array}$ & $\begin{array}{l}\text { Ballooning } \\
\text { (Score) }\end{array}$ & $\begin{array}{l}\text { Steatosis } \\
(\% \rrbracket\end{array}$ & $\begin{array}{l}\text { TBIL } \\
(\mathrm{mg} / \mathrm{dl})\end{array}$ & $\begin{array}{l}\text { ALT } \\
(\mathrm{u} / \mathrm{I})\end{array}$ & $\begin{array}{l}\text { AST } \\
(\mathrm{u} / \mathrm{I})\end{array}$ \\
\hline \multirow[t]{3}{*}{ BDL } & 0 & 8 & $\begin{array}{l}80.22 \pm \\
4.34\end{array}$ & $\begin{array}{l}0.34 \pm \\
0.27\end{array}$ & $0.00 \pm 0.00$ & $\begin{array}{l}0.00 \pm \\
0.00\end{array}$ & $\begin{array}{l}0.00 \\
\pm 0.00\end{array}$ & $\begin{array}{l}0.93 \pm \\
0.42\end{array}$ & $\begin{array}{l}25.37 \pm \\
8.48\end{array}$ & $\begin{array}{l}88.62 \pm \\
13.41\end{array}$ \\
\hline & 6 & 8 & $\begin{array}{l}86.31 \pm \\
4.10\end{array}$ & $\begin{array}{l}3.25 \pm \\
1.04\end{array}$ & $1.25 \pm 0.46$ & $\begin{array}{l}0.38 \pm \\
0.52\end{array}$ & $\begin{array}{l}4.75 \pm \\
2.87\end{array}$ & $\begin{array}{l}128.32 \\
\pm 40.52\end{array}$ & $\begin{array}{l}137.25 \pm \\
42.61\end{array}$ & $\begin{array}{l}612.37 \pm \\
108.67\end{array}$ \\
\hline & 10 & 8 & $\begin{array}{l}92.75 \pm \\
7.02\end{array}$ & $\begin{array}{l}10.63 \pm \\
3.20\end{array}$ & $1.88 \pm 0.35$ & $\begin{array}{l}0.50 \pm \\
0.53\end{array}$ & $\begin{array}{l}6.63 \pm \\
1.85\end{array}$ & $\begin{array}{l}133.42 \\
\pm 16.12\end{array}$ & $\begin{array}{l}127.87 \pm \\
62.50\end{array}$ & $\begin{array}{l}775.25 \\
\pm 384.59\end{array}$ \\
\hline \multirow{2}{*}{$\begin{array}{l}\text { Reversal } \\
\text { Operation }\end{array}$} & 6 & 8 & $\begin{array}{l}85.60 \pm \\
3.64\end{array}$ & $\begin{array}{l}6.50 \pm \\
2.14\end{array}$ & $1.00 \pm 0.75$ & $\begin{array}{l}0.38 \pm \\
0.52\end{array}$ & $\begin{array}{l}5.25 \pm \\
2.43\end{array}$ & $\begin{array}{l}6.17 \pm \\
4.94\end{array}$ & $\begin{array}{l}32.00 \\
\pm 11.46\end{array}$ & $\begin{array}{l}156.13 \\
\pm 70.12\end{array}$ \\
\hline & 13 & 8 & $\begin{array}{l}83.80 \pm \\
3.77\end{array}$ & $\begin{array}{l}4.13 \pm \\
1.81\end{array}$ & $0.50 \pm 0.53$ & $\begin{array}{l}0.13 \pm \\
0.35\end{array}$ & $\begin{array}{l}4.50 \pm \\
2.45\end{array}$ & $\begin{array}{l}1.95 \pm \\
0.63\end{array}$ & $\begin{array}{l}28.50 \pm \\
7.50\end{array}$ & $\begin{array}{l}132.25 \\
\pm 39.98\end{array}$ \\
\hline$p$ & & & $<0.001$ & $<0.001$ & $<0.001$ & $<0.001$ & $<0.001$ & $<0.001$ & $<0.001$ & $<0.001$ \\
\hline
\end{tabular}

BDL: Biliary duct ligation. P: One-way analysis of variance (ANOVA) for multiple group comparisons of parameters. 


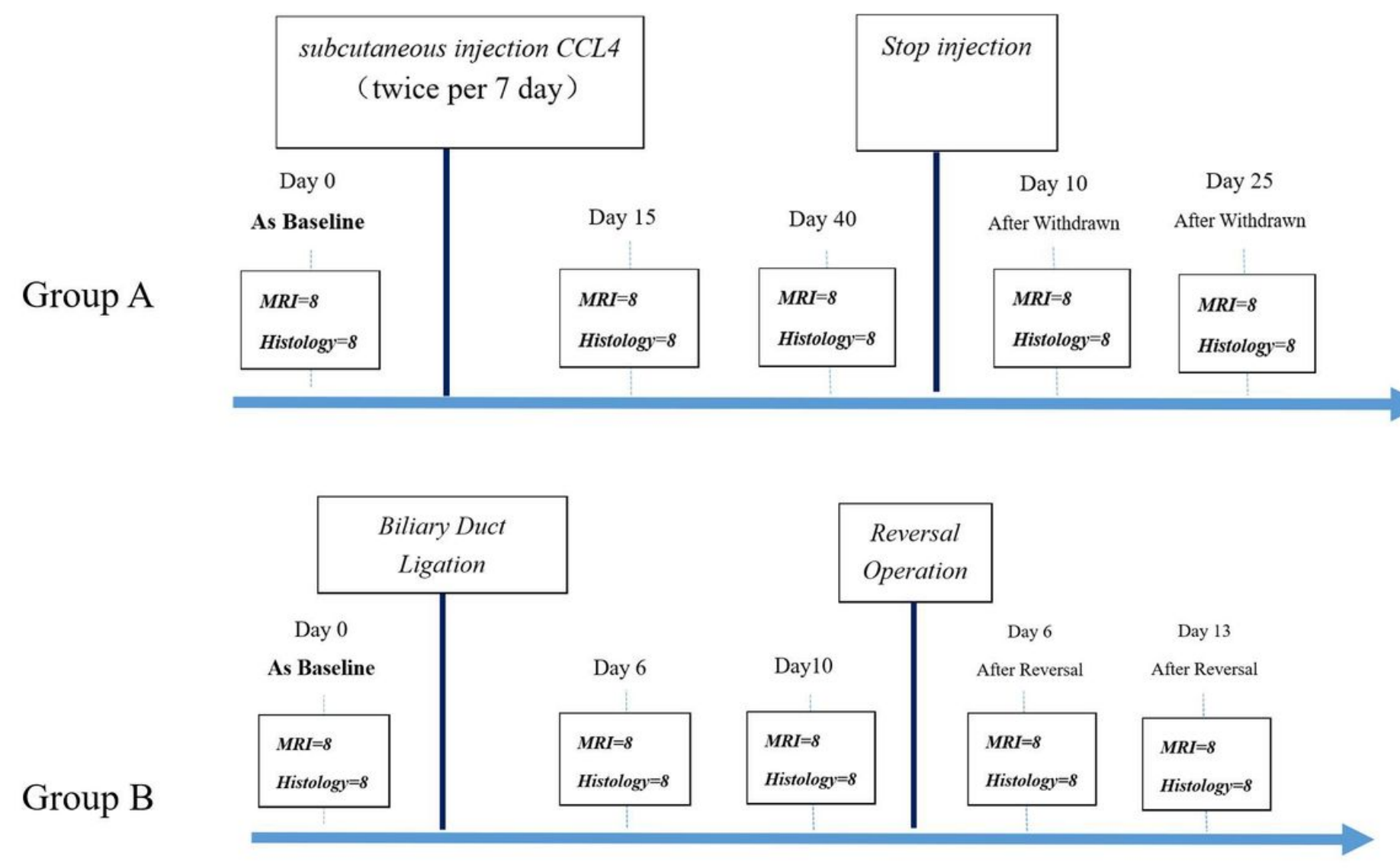

Figure 1

Schematic of group A (carbon tetrachloride) and group B (bile duct ligation).

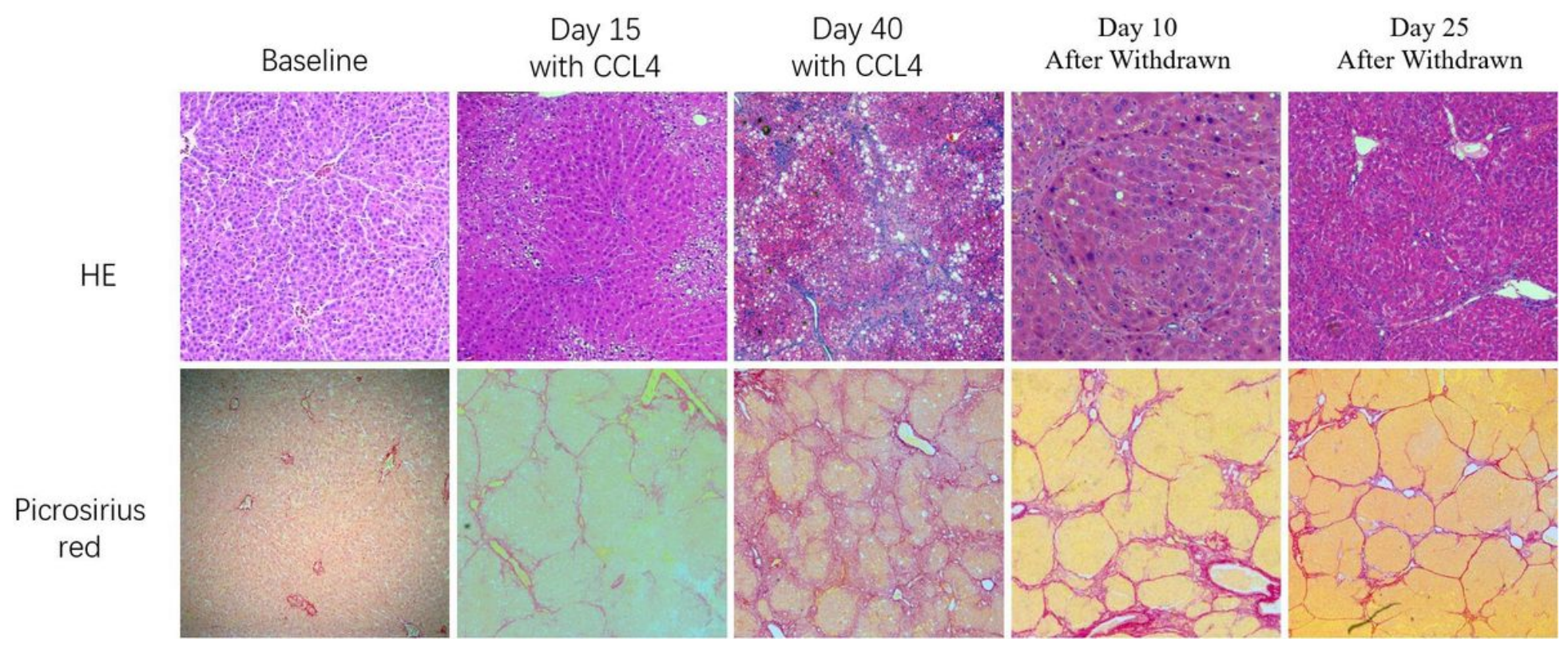

Figure 2

Hematoxylin and eosin (HE) staining and picrosirius red staining for representative samples in group A (carbon tetrachloride). 

Baseline
Day 6
Day 10
with $\mathrm{BDL}$
with $\mathrm{BDL}$
Day 6
After Reversal
Day 13
After Reversal

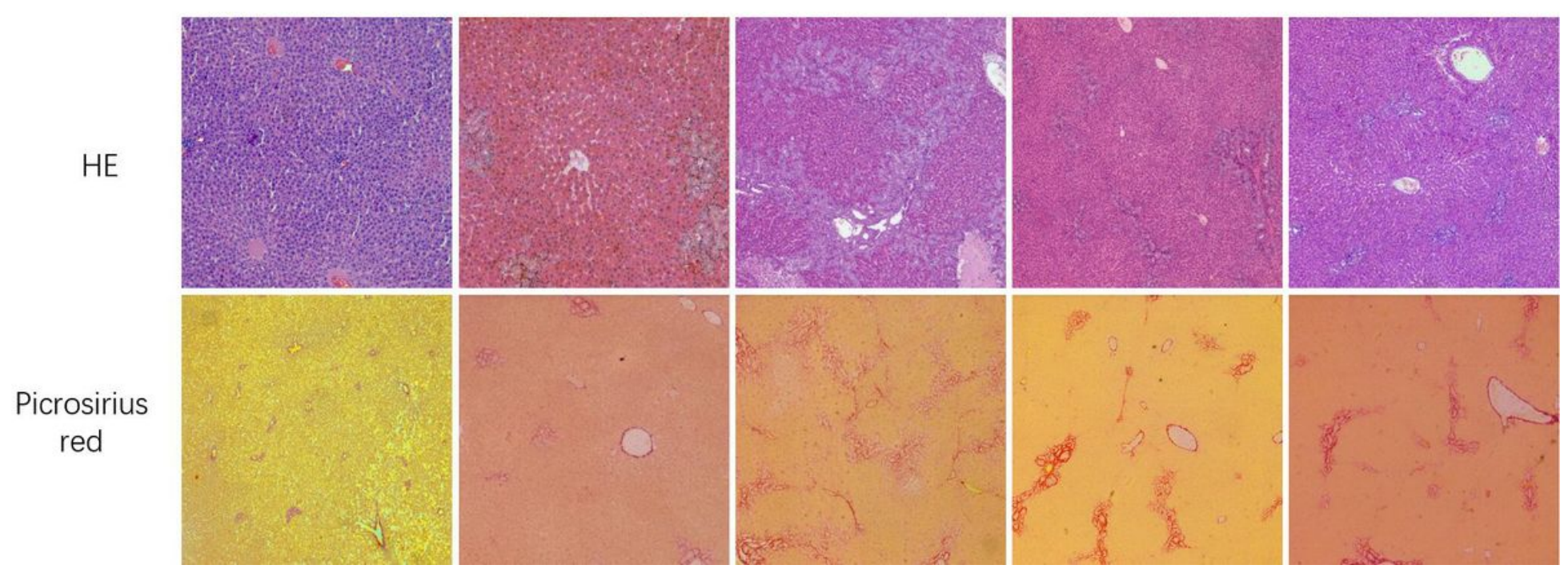

Figure 3

Hematoxylin and eosin (HE) staining and picrosirius red staining for representative samples in group B (bile duct ligation).

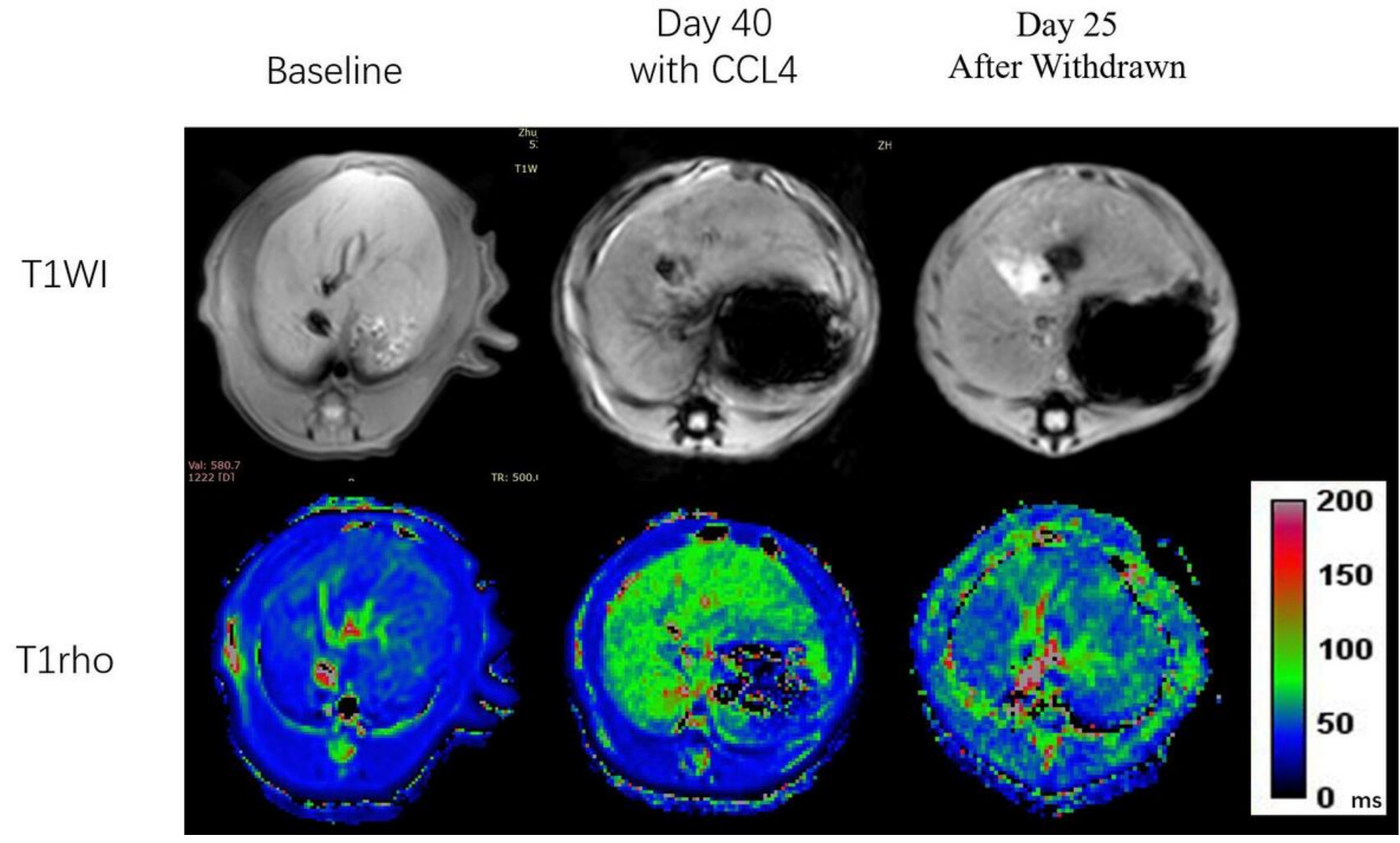

Figure 4

Liver axial MR images for group A (carbon tetrachloride). 


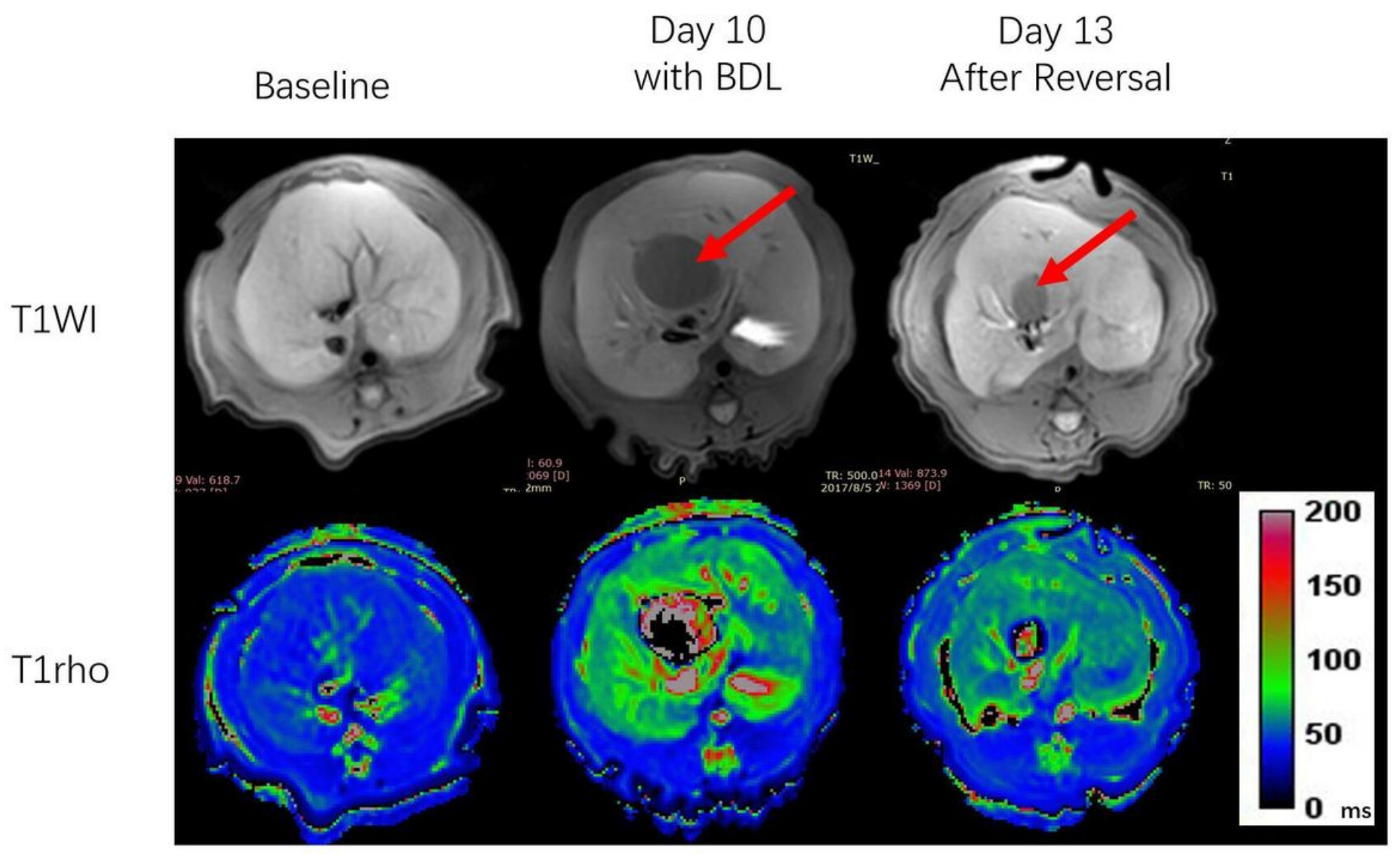

Figure 5

Liver axial MR images for group B(bile duct ligation), red arrows = dilated biliary duct. 